\title{
Hemispheric asymmetry in temporal resolution: Contribution of the magnocellular pathway
}

\author{
MATIA OKUBO \\ Sophia University, Tokyo, Japan \\ and University of Melbourne, Melbourne, Australia \\ and \\ MICHAEL E. R. NICHOLLS \\ University of Melbourne, Melbourne, Australia
}

\begin{abstract}
Right-handed participants performed simple visual judgments on nonverbal stimuli presented either to the left visual field-right hemisphere (LVF-RH) or to the right visual field-left hemisphere (RVF-LH). The stimuli were exposed for $40-120 \mathrm{msec}$, followed by a backward mask. When the stimuli were presented against a green background, an RVF-LH advantage was observed for the shortest exposure duration. This result supports the notion that the LH has finer temporal resolution than the RH. Imposition of a red background disrupted performance and eliminated the RVF-LH advantage for the shortest exposure duration. Because the red background attenuates functions of the magnocellular pathway, these results suggest that the magnocellular pathway contributes to the LH advantage for fine temporal resolution.
\end{abstract}

Considerable evidence supports the idea that the left hemisphere $(\mathrm{LH})$ has finer temporal resolution than the right hemisphere (RH; for reviews, see Hammond, 1982; Nicholls, 1996). In the visual modality, the right visual field-left hemisphere (RVF-LH) advantage has been found for a variety of tasks, such as flicker fusion (see, e.g., Goldman, Lodge, Hammer, Semmes, \& Mishkin, 1968), gap detection (see, e.g., Nicholls, 1994), perception of simultaneity (see, e.g., Efron, 1963; Nicholls, 1994), and temporal order judgment (see, e.g., Swisher \& Hirsh, 1972).

The inspection time task, originally developed by Vickers (1979), has been used to investigate the RVF-LH advantage for fine temporal resolution (Elias, BulmanFleming, \& McManus, 1999; Elias, Saucier, \& Engebregtson, 2002; Nicholls \& Atkinson, 1993; Nicholls \& Cooper, 1991). In this task, the stimulus pattern, consisting of an inverted U-shaped figure with one leg shorter than the other (referred to as a $p i$ figure), is presented for various exposure durations followed by a backward mask. Participants are asked to indicate which leg in the pi figure is shorter. Using a visual half-field paradigm, Nicholls and Cooper found that responses for shorter durations (40-60 msec) were significantly more accurate when the stimuli were presented to the RVF-LH than to the left visual field-right hemisphere (LVF-RH). This finding

This research was supported by the Japan Society for the Promotion of Science and a grant from MEXT Japan to the first author. Reprint requests should be sent to Matia Okubo, Department of Psychology, University of Melbourne, Parkville, VIC 3010, Australia (e-mail: mokubo $@$ @unimelb.edu.au). was replicated in several studies (Elias et al., 1999; Elias et al., 2002; Nicholls \& Atkinson, 1993) and supports the notion that the LH has finer temporal resolution than the RH (for critique and further discussion, see Elias et al., 2002; Sadler \& Deary, 1996).

Electrophysiological studies have also shown hemispheric asymmetries in temporal resolution. Mecacci and Spinelli (1987) demonstrated that the amplitude of visualevoked potentials (VEPs) was larger in the LH than in the RH when the stimuli had higher temporal and lower spatial resolution; the reverse was found when the stimuli had lower temporal and higher spatial resolution (also see Mecacci, 1993, 1997; Mecacci, Spinelli, \& Viggiano, 1990; Rebai, Mecacci, Bagot, \& Bonnet, 1986). These results suggest that the hemispheric asymmetries in VEP are linked to the functions of two distinct visual channelstransient and sustained-as hypothesized in the psychophysics literature (see, e.g., Kulikowski \& Tolhurst, 1973; Tolhurst, 1975). The transient channel has higher temporal and lower spatial resolution and is especially activated by motion and flickering stimuli. The sustained channel has lower temporal and higher spatial resolution and is especially activated by spatial properties of stimuli. Based on these results, Mecacci (1997) hypothesized that the $\mathrm{LH}$ and the $\mathrm{RH}$ use the information derived by the transient and sustained channels, respectively (but see Grabowska \& Nowicka, 1996, for hemispheric differences for spatial characteristics of the two channels).

Livingstone and Hubel (1987) found that the cells in the magnocellular and parvocellular pathways have similar temporal and spatial characteristics to those of the transient and the sustained channels, respectively. These 
pathways are distinct visual-processing streams originating in the retinal ganglion cells and the lateral geniculate nucleus. Livingstone and Hubel (1987) hypothesized that the magnocellular and parvocellular pathways in primates were the neural analogs of the transient and sustained channels, respectively. The separation of the two pathways is no longer considered to be complete, and thus some researchers have questioned the functional role of two distinct pathways in visual perception (see, e.g., Cavanagh \& Anstis, 1991). However, the functional characteristics of the two pathways are preserved in the visual cortex and have considerable effect on visual performance (for a review, see Van Essen \& De Yoe, 1995). In fact, researchers have reported that inhibiting the magnocellular pathway by imposing a red background disrupts the performance of behavioral tasks that require processing of higher temporal resolution, such as metacontrast masking or stroboscopic motion (Breitmeyer, May, \& Heller, 1991; Breitmeyer \& Williams, 1990), or processing of lower spatial resolution, such as in detection of larger sized patches or global precedence effects (Breitmeyer \& Breier, 1994; Michimata, Okubo, \& Mugishima, 1999). The disruptive effect of the red background is based on the fact that the magnocellular pathway selectively contains cells that have receptive fields with a tonic red surround mechanism (type IV cells). That is, imposing diffuse red light causes a tonic suppression of these cells' excitatory activities (see de Monasterio, 1978; de Monasterio \& Schein, 1980; Livingstone \& Hubel, 1984; Wiesel \& Hubel, 1966).

The present experiment employed this background color manipulation to examine the role of the magnocellular pathway in hemispheric asymmetries in temporal resolution. Assuming that the transient channel and the magnocellular pathway are functionally related, we hypothesized that processing of the magnocellular pathway contributes to the LH advantage for fine temporal resolution. To test this hypothesis, we performed an inspection time task in LVF-RH and RVF-LH trials and compared results for green backgrounds (i.e., the control) with those for red backgrounds.

\section{METHOD}

\section{Participants}

Thirty-three college students at Sophia University (23 females, 10 males) received an extra course credit for participation. They all reported having normal or corrected-to-normal visual acuity and normal color vision. Normal color vision was confirmed by the Ishihara (1968) test for color blindness. All of the participants were right-handed with no left-handed relatives in their immediate families. Handedness was assessed with the Edinburgh Handedness Inventory (Oldfield, 1971).

\section{Design}

The experiment was a 2 (visual field: LVF-RH vs. RVF-LH) $\times$ 2 (background color: green vs. red) $\times 4$ (exposure duration: 40-, 67-, 93-, or 120-msec) factorial design. All variables were manipulated within participants. The dependent variable was the percent- age of correct trials. Hemispheric asymmetries in temporal resolution have been observed mainly for accuracy data (see Nicholls, 1996). In view of this, this experiment emphasized accuracy and did not require speeded responses (see Procedure section). Because of this, reaction time can provide only equivocal information and thus was not used as a dependent variable.

\section{Apparatus}

An NEC 17-in. multisynch display and an Apple Macintosh Powerbook 5300 were used for the presentation of the stimuli and for recording participants' responses. The experiment was controlled by a MacProbe software package (Hunt, 1994). A 10-key pad (Sanwa Supply NT-MAC 2) was connected to the computer and served as a 4-key response console. A Minolta CS-100A was used to measure luminance and chromaticity.

\section{Procedure}

The experiment consisted of two phases: flicker photometry and the inspection time task. In both phases, participants were seated in a dark room approximately $57 \mathrm{~cm}$ away from the display, with their head positioned by a chin rest.

Flicker photometry. Participants were dark adapted for $10 \mathrm{~min}$ prior to the experiment. On each trial, a fixation dot appeared at the center of the display with two square patches $\left(3^{\circ} \times 3^{\circ}\right.$ of visual angle), placed to the left and the right of the fixation against a black background $\left(0.01 \mathrm{~cd} / \mathrm{m}^{2}\right)$. The centermost edge of each patch was $2^{\circ}$ away from the fixation. The color of the patches was alternated between red and green in a temporal square wave manner at a rate of $12.50 \mathrm{~Hz}$. The luminance of the red patches was constant throughout the experimental session $\left(4.00 \mathrm{~cd} / \mathrm{m}^{2}, \mathrm{CIE} x\right.$-, $y$-coordinates $=.636$, .336). Participants were asked to adjust the luminance intensity of the green patches to find the particular point at which heterochromatic flicker was eliminated or minimized. There were six sessions consisting of three ascending and three descending sequences. Each participant performed ascending and descending sequences alternately. Two practice sessions were given prior to the task. For each individual participant, the average luminance value of the six sessions was computed and used for the green background in the inspection time task $\left(M=4.30 \mathrm{~cd} / \mathrm{m}^{2}, \mathrm{CIE} x\right.$-, $y$-coordinates $\left.=.279, .602\right)$.

Inspection time task. The inspection time task began immediately after the flicker photometry. Basic features of the inspection task approximated those of Nicholls and Atkinson (1993, the temporal version). At the beginning of the inspection time task, participants were told to direct their gaze toward the fixation point and to maintain their fixation until after they had made their responses. They were also asked to keep their index and middle fingers of both hands on the four-key response panel. The importance of response accuracy, not response speed, was emphasized.

The stimuli in the inspection time task were configurations of the same basic pi figure, which subtended $2.3^{\circ}$ in width and $3.0^{\circ}$ in height (Figure 1A). Either the left or the right leg of the pi figure was $1.7^{\circ}$ shorter than the other leg (for further information, see Nicholls \& Atkinson, 1993; Nicholls \& Cooper, 1991). The stimuli were presented in black $\left(0.01 \mathrm{~cd} / \mathrm{m}^{2}\right)$ against the red or the equiluminant green background (see the Flicker Photometry section above).

At the beginning of each trial, the display turned to uniform red or green for $1,000 \mathrm{msec}$. The fixation dot appeared at the center of the display for $53 \mathrm{msec}$. Although the duration of this fixation point was brief, the fact that it occurred in the same place and that the intertrial interval was long should have allowed for accurate fixation. Then, the $p i$ figure was presented to either the right or the left visual field for $40,67,93$, or $120 \mathrm{msec}$. The centermost edge of each $p i$ figure was $2.3^{\circ}$ away from the fixation. Immediately after the stimulus was exposed, the pi figure was replaced by a similar backward mask with both legs of equal length (Figure 1B). Participants responded simultaneously with the rightmost finger of each hand to 


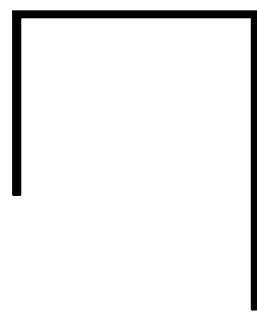

A

Figure 1. Examples of the stimulus patterns. The pi figure (A) and its backward mask (B).

indicate that the right leg had been shorter and with the leftmost finger of each hand to indicate that the left leg had been shorter (see Bradshaw \& Nettleton, 1983, p. 83, for a discussion of advantage of bimanual responses). Prior to the task, 10 practice trials were given to familiarize participants with the experimental procedure.

Participants received a total of 576 trials, which were divided into 12 blocks of 48 trials. Each block consisted of an orthogonal combination of two visual fields, two colors, four exposure durations, and two leg conditions (32 trials). In addition, one replication was administered for the exposure conditions of 40 and $67 \mathrm{msec}$ (16 trials). This was done because previous studies had suggested that these duration conditions were the least vulnerable to floor and ceiling effects. Participants received a short break after each block. The trial order was randomized for each block. The color condition was randomized by trial, not block, to avoid possible side effects of blocked color manipulation. If the time course of adaptation varies for different colors, perceptual equiluminance may not be maintained after a continuous presentation of a single-color background.

\section{RESULTS}

For each participant, the percentage of correct trials was computed for the 16 experimental conditions described in the Design section. Percentage of correct trials was subjected to a 2 (visual field: LVF-RH vs. $\mathrm{RVF}-\mathrm{LH}) \times 2$ (background color: green vs. red) $\times 4$ (exposure duration: 40, 67, 93, or $120 \mathrm{msec}$ ) repeated measures analysis of variance (ANOVA).

Responses were significantly more accurate for the RVF-LH trials than for the LVF-RH trials $[F(1,32)=$ $4.07, p=.05$ ] (see Figure 2). There was a significant main effect of background color $[F(1,32)=5.27, p=$ $.03]$, indicating that accuracy was decreased for the red background. There was also a significant main effect of exposure duration $[F(3,96)=111.52, p<.001]$, indicating that responses were more accurate for the longer exposure duration.

There was a significant background color $\times$ exposure duration interaction $[F(3,96)=6.47, p<.001]$, indicating that the decrease produced by the red background was observed mainly for the shortest exposure duration (i.e., $40 \mathrm{msec}$ ). This interaction was qualified by visual field $\times$ background color $\times$ exposure duration interaction $[F(3,96)=4.87, p=.003]$. This three-way interaction suggests that the visual field $\times$ exposure duration interaction differs between the red and the green backgrounds.
To investigate the three-way interaction, a separate visual field $\times$ exposure duration repeated measures ANOVA was conducted for each background color. Figure 2 (upper panel) shows the results of the green background condition. Responses were significantly more accurate for the RVF-LH trials than for the LVF-RH trials when the stimuli were presented against the green background $[F(1,32)=5.68, p=.02]$. There was a significant visual field $\times$ exposure duration interaction, indicating that the RVF-LH advantage was observed mainly for the shortest duration $[F(3,96)=5.05, p=.003]$. Compared with the green background, the red background produced neither the significant main effect of visual field nor the visual field $\times$ exposure duration interaction $(F \mathrm{~s}<1.66$; see Figure 2, lower panel).
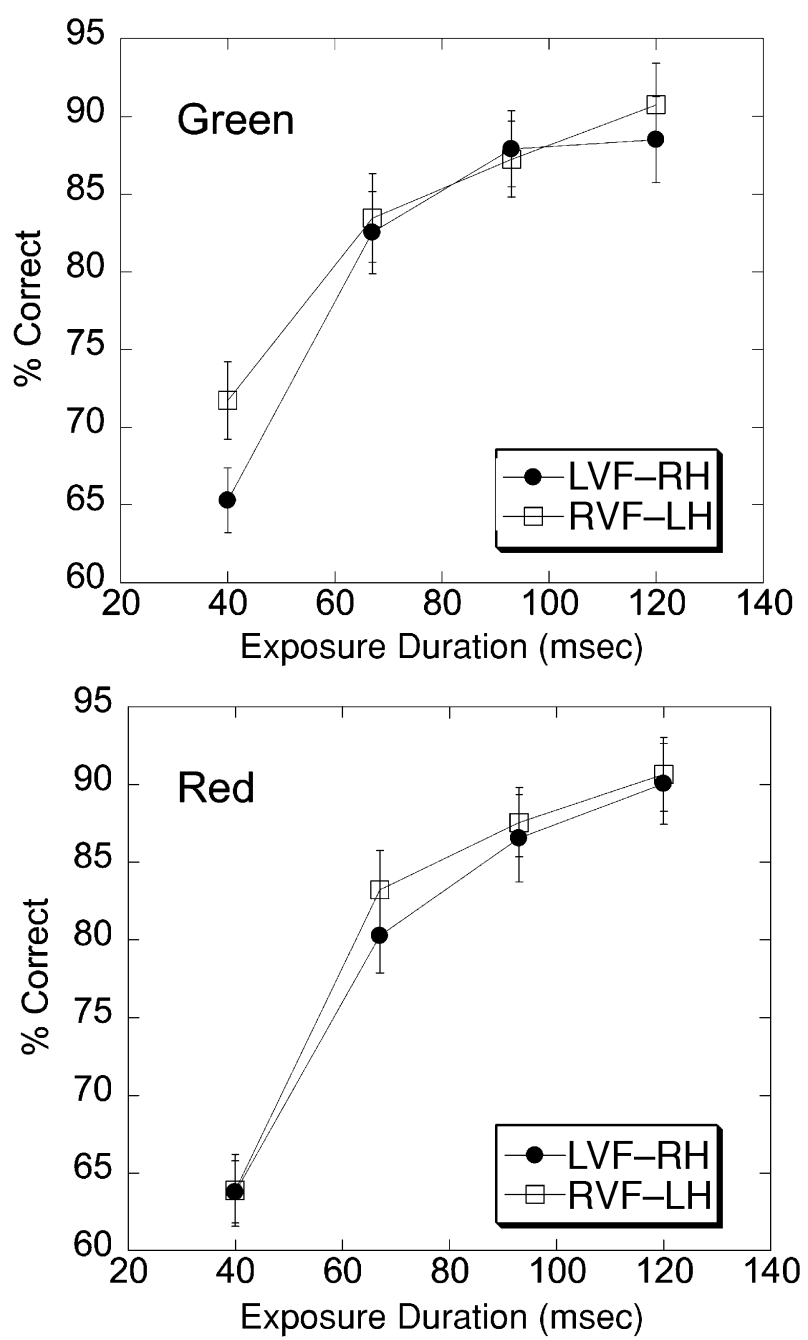

Figure 2. Mean percentages of correct trials in the inspection time task on the LVF-RH and RVF-LH trials as a function of exposure duration. The results for the green and red backgrounds are presented in the upper and lower panels, respectively. Error bars show standard errors. 


\section{DISCUSSION}

The RVF-LH advantage was replicated for the inspection time task when the stimuli were presented against the green background (see Elias et al., 1999; Elias et al., 2002; Nicholls \& Atkinson, 1993; Nicholls \& Cooper, 1991). This advantage was most pronounced for the shortest exposure duration (i.e., $40 \mathrm{msec}$ ), supporting the idea that the LH has finer temporal resolution than the RH.

The red background disrupted the performance of the inspection time task, particularly for the shortest exposure duration. These results are consistent with those of Breitmeyer and his colleagues (Breitmeyer et al., 1991; Breitmeyer \& Williams, 1990), who reported that the imposition of a red background disrupts the performance of tasks (e.g., metacontrast masking and stroboscopic motion) requiring high temporal resolution. As shown in Figure 2 for the 40-msec condition, this disruptive effect was larger for the RVF-LH trials than for the LVF-RH trials and eliminated the RVF-LH advantage. Because the red background is known to produce suppressive effects on magnocellular function (de Monasterio, 1978; de Monasterio \& Schein, 1980; Livingstone \& Hubel, 1984; Wiesel \& Hubel, 1966), these results support the hypothesis that processing of the magnocellular pathway contributes to the $\mathrm{LH}$ advantage for fine temporal resolution.

The type TV cells, which are suppressed by the diffuse red light (e.g., the red background), have been found in low-level sensory areas, such as retinal ganglion cells, LGN, and area 17 of primates' magnocellular pathway (de Monasterio, 1978; de Monasterio \& Schein, 1980; Livingstone \& Hubel, 1984; Wiesel \& Hubel, 1966). These findings suggest that the suppressive effects of the red background occur at early sensory levels and that the activities of these areas somehow contribute to the $\mathrm{LH}$ advantage for fine temporal resolution. One possibility is that the anatomical projection of the magnocellular pathway is biased to the $\mathrm{LH}$ at the early sensory levels, such as area 17. However, a number of researchers (e.g., Hellige, 1997; Hellige \& Cumberland, 2001; Kosslyn, Anderson, Hillger, \& Hamilton, 1994; Roth \& Hellige, 1998) have questioned the idea of anatomical asymmetries of the magnocellular pathway. Furthermore, there has been no evidence of anatomical asymmetries of the magnocellular pathway, at least to the authors' knowledge. Thus, it may be more reasonable to consider that the hemispheric asymmetry in temporal resolution may depend on higher levels of processing. A second possibility is that the high-level cognitive mechanisms in the $\mathrm{LH}$, such as pattern recognition mechanisms in the inferotemporal cortex (Goodale \& Millner, 1992), may select and process information with higher temporal resolution derived by the magnocellular pathway more efficiently than those in the RH under normal viewing conditions. When the magnocellular pathway is inhibited and such information cannot be used, the LH advantage may be eliminated. This interpretation is compatible with VEP findings showing that the LH advantage for higher temporal resolution arises at temporal or occipital-temporal levels, but not at early occipital levels (see Mecacci, 1997).

The decrease in accuracy with shorter durations suggests that the perception of the stimulus was being degraded. Various forms of perceptual degradation affect visual field differences (see Sergent, 1983; Sergent \& Hellige, 1986). One might argue that differences in perceptibility between the exposure durations, not temporal resolution, contribute to the RVF-LH advantage for the inspection task. However, perceptual degradation usually disrupts the RVF-LH rather than the LVF-RH and produces a LVF-RH advantage. This is precisely the opposite of the RVF-LH advantage found for the shortest duration in the present study.

RVF-LH advantages have been observed for some types of spatial processing, such as processing of categorical spatial relations, local elements, or high spatial frequency (see, e.g., Hellige, 1993, 1996; Okubo \& Michimata, 2002). It is, therefore, possible that the RVF-LH advantage for the inspection time task can be attributed to categorical spatial characteristics of the task (i.e., judgment of relative position). However, categorical spatial processing is not affected by inhibition of the magnocellular pathway (Hellige \& Cumberland, 2001; Roth \& Hellige, 1998). The parvocellular pathway, in contrast, may provide more useful information for categorical spatial processing (Cowin \& Hellige, 1994) and its LH advantage (Okubo \& Michimata, 2004). In addition, Nicholls and Atkinson (1993) showed that manipulation of spatial properties did not produce a significant visual field difference in the inspection time task, whereas manipulation of temporal properties did. Finally, it is difficult to explain the interaction involving exposure duration in terms of the LH advantage for categorical spatial processing or other spatial hemispheric asymmetries. We, therefore, believe that the present results are reasonably explained, not by perceptibility or spatial hemispheric asymmetries, but rather by hemispheric asymmetry in temporal resolution and its relation to the magnocellular pathways.

\section{REFERENCES}

Bradshaw, J. L., \& Nettleton, N. C. (1983). Human cerebral asymmetry. Englewood Cliffs, NJ: Prentice Hall.

Breitmeyer, B. G., \& Breier, J. I. (1994). Effects of background color on reaction time to stimuli varying in size and contrast: Inference sabout human M channels. Vision Research, 34, 1039-1045.

Breitmeyer, B. G., May, J. G., \& Heller, S. S. (1991). Metacontrast reveals asymmetries at red-green isoluminance. Journal of the Optical Society of America, 8, 1324-1329.

Breitmeyer, B. G., \& Williams, M. C. (1990). Effects of isoluminantbackground color on metacontrast and stroboscopic motion: Interactions between sustained (P) and transient (M) channels. Vision Research, 30, 1069-1075.

CaVANAGH, P., \& ANSTIS, S. (1991). The contribution of color to motion in normal and color deficient observers. Vision Research, 31, 2109-2148.

Cowin, E. L., \& Hellige, J. B. (1994). Categorical versus coordinate spatial processing: Effects of blurring and hemispheric asymmetry. Journal of Cognitive Neuroscience, 6, 156-164. 
De Monasterio, F. M. (1978). Properties of concentrically organized $\mathrm{X}$ and $\mathrm{Y}$ ganglion cells of macaque retina. Journal of Neurophysiology, 41, 1394-1417.

de Monasterio, F. M., \& Schein, S. J. (1980). Protan-like spectral sensitivity of foveal Y ganglion cells of the retina of macaque monkeys. Journal of Physiology, 299, 385-396.

EFRON, R. (1963). The effect of handedness on the perception of simultaneity and temporal order. Brain, 86, 261-284.

Elias, L. J., Bulman-Fleming, M. B., \& McManus, I. C. (1999). Visual temporal asymmetries are related to asymmetries in linguistic perception. Neuropsychologia, 37, 1243-1249.

Elias, L. J., SAUCIER, D. M., \& Engebregtson, D. (2002). Lateral differences in visual inspection time? The role of apparent motion cues. Brain \& Cognition, 48, 342-347.

Goldman, P. S., Lodge, A., Hammer, L. R., Semmes, J., \& Mishin, M. (1968). Critical flicker frequency after unilateral temporal lobectomy in man. Neuropsychologia, 6, 355-366.

Goodale, M. A., \& Millner, A. D. (1992). Separate visual pathways for perception and action. Trends in Neurosciences, 15, 20-25.

Grabowska, A., \& NowicKA, A. (1996). Visual-spatial-frequency model of cerebral asymmetry: A critical survey of behavioral and electrophysiological studies. Psychological Bulletin, 120, 434-449.

Hammond, G. R. (1982). Hemispheric differences in temporal resolution. Brain \& Cognition, 1, 95-118.

Hellige, J. B. (1993). Hemispheric asymmetry: What's right and what's left. Cambridge, MA: Harvard University Press.

Hellige, J. B. (1996). Hemispheric asymmetry for visual information processing. Acta Neurobiologiae Experimentalis (Warsaw), 56, 485497.

Hellige, J. B. (1997). Hemispheric asymmetry for components of spatial processing. In S. Christman (Ed.), Cerebral asymmetries in sensory and perceptual processing (pp. 83-124). Amsterdam: Elsevier, North-Holland.

Hellige, J. B., \& Cumberland, N. (2001). Categorical and coordinate spatial processing: More on contributions of the transient/magnocellular visual system. Brain \& Cognition, 45, 155-163.

Hunt, S. M. J. (1994). MacProbe: A Macintosh-based experimenter's workstation for the cognitive sciences. Behavior Research Methods, Instruments, \& Computers, 26, 345-351.

IsHIHARA, S. (1968). Tests for colour-blindness. Tokyo: Kanehara Shuppan.

Kosslyn, S. M., Anderson, A. K., Hillger, L. A., \& Hamilton, S. E. (1994). Hemispheric differences in sizes of receptive fields or attentional biases? Neuropsychology, 8, 139-147.

Kulikowski, J. J., \& Tolhurst, D. J. (1973). Psychophysical evidence for sustained and transient detectors in human vision. Journal of Physiology, 232, 149-162.

LiVINGSTONE, M. S., \& HUBEL, D. H. (1984). Anatomy and physiology of a color system in the primate visual cortex. Journal of Neuroscience, 4, 309-359.

LivingSTONe, M. S., \& Hubel, D. H. (1987). Psychophysical evidence for separate channels for the perception of form, color, motion, and depth. Journal of Neuroscience, 7, 3416-3468.

MECACCI, L. (1993). On spatial frequencies and cerebral hemispheres: Some remarks from the electrophysiological and neuropsychological points of view. Brain \& Cognition, 22, 199-212.

MecaCCI, L. (1997). Temporal frequency processing. In S. Christman
(Ed.), Cerebral asymmetries in sensory and perceptual processing (pp. 31-54). Amsterdam: Elsevier, North-Holland.

MecaCcI, L., \& SpINelli, D. (1987). Hemispheric asymmetry of pattern reversal visual evoked potentials in healthy subjects. International Journal of Psychophysiology, 4, 325-328.

MECACCI, L., SPINELLI, D., \& ViggianO, M. (1990). The effects of visual field size on hemispheric asymmetry of pattern reversal visual evoked potentials. International Journal of Neuroscience, 51, 141-151.

Michimata, C., OKubo, M., \& Mugishima, Y. (1999). Effects of background color on the global and local processing of hierarchically organized stimuli. Journal of Cognitive Neuroscience, 11, 1-8.

NicholLs, M. E. R. (1994). Hemispheric asymmetries for temporal resolution: A signal detection analysis of threshold and bias. Quarterly Journal of Experimental Psychology, 47A, 291-310.

Nicholls, M. E. R. (1996). Evidence and implications of a temporal processing dichotomy between the hemispheres. Laterality, 1, 97-137.

Nicholls, M. E. R., \& AtKinson, J. (1993). Hemispheric asymmetries for an inspection time task: A general left hemisphere temporal advantage? Neuropsychologia, 31, 1181-1190.

Nicholls, M. E. R., \& CoOPER, C. J. (1991). Hemispheric differences in the rates of information processing for simple non-verbal stimuli. Neuropsychologia, 29, 677-684.

OKUBO, M., \& Michimata, C. (2002). Hemispheric processing of categorical and coordinate spatial relations in the absence of low spatial frequencies. Journal of Cognitive Neuroscience, 14, 291-297.

Окиво, М., \& Michimata, C. (2004). The role of high spatial frequencies on hemispheric processing of categorical and coordinate spatial relations. Journal of Cognitive Neuroscience, 16, 1576-1582.

OlDFIELD, R. C. (1971). The assessment and analysis of handedness: The Edinburgh inventory. Neuropsychologia, 9, 97-113.

Rebai, M., Mecacci, L., Bagot, J. D., \& Bonnet, C. (1986). Hemispheric asymmetries in the visual evoked potentials to temporal frequency: Preliminary evidence. Perception, 15, 589-594.

Roth, E. C., \& Hellige, J. B. (1998). Spatial processing and hemispheric asymmetry: Contributions of the transient/magnocellular visual system. Journal of Cognitive Neuroscience, 10, 472-484.

SAdLER, A. J., \& DeARY, I. J. (1996). Cerebral asymmetries in inspection time? Neuropsychologia, 34, 283-295.

SERGENT, J. (1983). Role of the input in visual hemispheric asymmetries. Psychological Bulletin, 93, 481-512.

Sergent, J., \& Hellige, J. B. (1986). Role of input factors in visual field asymmetries. Brain \& Cognition, 5, 174-199.

Swisher, L., \& Hirsh, I. J. (1972). Brain damage and the ordering of two temporally successive stimuli. Neuropsychologia, 10, 137-152.

Tolmurst, D. J. (1975). Sustained and transient channels in human vision. Vision Research, 15, 1151-1155.

VAn Essen, D. C., \& De Yoe, E. A. (1995). Concurrent processing in the primate visual cortex. In M. S. Gazzaniga (Ed.), The cognitive neurosciences (pp. 383-400). Cambridge, MA: MIT Press.

VICKERS, D. (1979). Decision processes in visual perception. New York: Academic Press.

Wiesel, T. N., \& Hubel, D. H. (1966). Spatial and chromatic interactions in the lateral geniculate body of the rhesus monkey. Journal of Neurophysiology, 29, 1115-1156.

(Manuscript received April 30, 2004; revision accepted for publication November 1, 2004.) 